\title{
Prostaglandin Inhibition Prevents the Fall in Pulmonary Vascular Resistance as a Result of Rhythmic Distension of the Lungs in Fetal Lambs
}

\author{
HARM VELVIS,' PHILLIP MOORE, AND MICHAEL A. HEYMANN \\ Cardiovascular Research Institute and Departments of Pediatrics, Physiology and Obstetrics, Gynecology, and \\ Reproductive Sciences, University of California San Francisco, San Francisco, California 94143
}

\begin{abstract}
Prostaglandins (PG) are vasoactive factors involved in the regulation of pulmonary vascular resistance at birth. However, their physiologic importance is unclear. We hypothesized that $P G$ are important regulators of pulmonary vascular resistance during static and rhythmic distension of the lungs. To test this hypothesis, we studied seven near-term fetal lambs treated with meclofenamate (a PG synthetase inhibitor) and six controls. The fetal lambs were instrumented on a long-term basis with vascular catheters to measure pulmonary arterial pressures, left atrial pressures, and pulmonary blood flow (radionuclidelabeled microsphere method). The fetal airway was intubated, and the ductus arteriosus wall was infiltrated with formalin to assure full patency during the study period. Pulmonary vascular resistance was calculated during baseline and during sequential in utero static distension of the fetal lungs, rhythmic distension, and ventilation with oxygenation. We found that during rhythmic distension, inhibition of PG synthesis abolished the 4-fold decrease in pulmonary vascular resistance seen in the control group. In contrast, during static distension, pulmonary vascular resistance did not change in either group, and during ventilation with oxygenation, pulmonary vascular resistance decreased 12-fold in both groups. We conclude that PG are important regulators of pulmonary vascular resistance during rhythmic distension but are not essential for the regulation of pulmonary vascular resistance during static distension or during ventilation with oxygenation. (Pediatr Res 30: 62-68, 1991)
\end{abstract}

Abbreviations

PG, prostaglandin

PGI 2, prostacyclin

The sudden and dramatic decrease in pulmonary vascular resistance that occurs at birth is essential for the normal transition from fetal to neonatal circulation (1). This decrease in pulmonary vascular resistance is regulated by a complex and incompletely understood interplay between metabolic and mechanical factors (2), which in turn are triggered by the ventilatory and circulatory changes that occur at birth. Prominent among the metabolic factors are the PG (3), products of arachidonic acid metabolism via the cyclooxygenase pathway. For example, $\mathrm{PGI}_{2}$, probably

Received November 16, 1990; accepted February 26, 1991.

Correspondence and reprint requests: Michael A. Heymann, M.D., Box 0544, HSE 1403, University of California San Francisco, San Francisco, CA 94143.

Supported by USPHS Grant HL-40473.

1 Present address: Bowman Gray School of Medicine, Department of Pediatrics (Cardiology), 300 South Hawthorne Road, Winston-Salem, NC 27103. the most important PG in the perinatal pulmonary circulation (3), is produced by the lungs of fetal goats and newborn lambs at the onset of mechanical ventilation (4) and at the onset of spontaneous breathing (5). However, inhibition of PG synthesis results in only moderate attenuation of the normal decrease in pulmonary vascular resistance at birth in acutely exteriorized full-term fetal goats (6) and in newborn lambs that were instrumented on a long-term basis (7). Therefore, the physiologic importance of PGs in the regulation of the perinatal pulmonary vascular resistance has been questioned (7).

To put these observations in perspective, an understanding of the ventilatory and circulatory changes that occur simultaneously with the fall in pulmonary vascular resistance at birth is essential. These changes include rhythmic distension of the lungs, removal of fluid from the alveolar spaces, and changes in $\mathrm{pH}$, arterial $\mathrm{O}_{2}$ tension, cardiac output, and systemic arterial pressures. All these changes, individually or in various combinations, can influence pulmonary vascular resistance. For instance, both rhythmic distension without oxygenation $(8,9)$ and oxygenation without ventilation (10) decrease pulmonary vascular resistance. These findings suggest that different mechanisms may be responsible for the fall in pulmonary vascular resistance during rhythmic distension and oxygenation. Additionally supporting this possibility are the findings that $\mathrm{PGI}_{2}$ is produced by the lungs during rhythmic distension (11) and that inhibition of PGs does not change pulmonary vasodilation in response to oxygenation without ventilation (10).

Therefore, we hypothesized that PGs are important regulators of pulmonary vascular resistance during rhythmic distension of the lungs but not necessarily during oxygenation. In addition, we anticipated that PGs could be regulators of pulmonary vascular resistance during a different mode of distending the lungs: static distension. To test these hypotheses, we studied near-term fetal lambs treated with meclofenamate, a PG synthetase inhibitor, and controls in a specific model that allowed in utero ventilation without changes in the diameter of the ductus arteriosus. This model has the advantage that effects of specific ventilatory interventions on pulmonary vascular resistance can be studied without the confounding effects of other birth-related phenomena affecting pulmonary vascular resistance, such as cooling, changes in $\mathrm{pH}$, systemic arterial pressure, cardiac output (12), and constriction of the ductus arteriosus.

\section{MATERIALS AND METHODS}

Animals. Thirteen near-term fetal lambs of 13 mixed Western ewes were studied. The fetal lambs (132-137 d, term, $145 \mathrm{~d})$ were of normal weight $(3.9 \pm 0.5 \mathrm{~kg})$ (mean $\pm \mathrm{SD}$ ) and had normal acid-base status (Table 1). The studies were performed 1 to $3 \mathrm{~d}$ after surgery. The study protocol was approved by the 
PG AND PERINATAL PVR IN FETAL LAMBS

Table 1. $\mathrm{pH}, \mathrm{PCO}_{2}, \mathrm{PO}_{2}, \mathrm{SO}_{2}$, and $\mathrm{Hb}$ in descending aorta of fetal lambs treated with meclofenamate*

\begin{tabular}{|c|c|c|c|c|c|c|}
\hline & $\begin{array}{l}\text { Baseline } \\
\text { before } 4 \mathrm{~h} \\
\text { infusion }\end{array}$ & $\begin{array}{l}\text { Baseline } \\
\text { after } 4 \mathrm{~h} \\
\text { infusion }\end{array}$ & $\begin{array}{l}\text { Distension with } \\
\text { nitrogen (static } \\
\text { distension) }\end{array}$ & $\begin{array}{l}\text { Ventilation with ni- } \\
\text { trogen (rhythmic dis- } \\
\text { tension) }\end{array}$ & $\begin{array}{l}\text { Ventilation } \\
\text { with room air } \\
\text { (ventilation }+ \\
\text { oxygenation) }\end{array}$ & $\begin{array}{l}\text { Ventilation } \\
\text { with } 100 \% \\
\quad \mathrm{O}_{2} \\
\end{array}$ \\
\hline \multicolumn{7}{|c|}{ Meclofenamate-treated fetal lambs $(n=7)$} \\
\hline $\mathrm{pH}$ & $7.37 \pm 0.03$ & $7.38 \pm 0.04$ & $7.36 \pm 0.05$ & $7.35 \pm 0.06$ & $7.41 \pm 0.10$ & $7.37 \pm 0.12$ \\
\hline $\mathrm{PCO}_{2}(\mathrm{kPa})$ & $7.4 \pm 1.0$ & $7.0 \pm 0.5$ & $6.9 \pm 0.5$ & $6.9 \pm 0.5$ & $5.9 \pm 1.7$ & $6.4 \pm 2.2$ \\
\hline $\mathrm{PO}_{2}(\mathrm{kPa})$ & $2.7 \pm 0.4$ & $2.8 \pm 0.3$ & $2.8 \pm 0.4$ & $2.7 \pm 0.4$ & $5.9 \pm 0.8+\ddagger$ & $42.8 \pm 22.1+$ \\
\hline $\mathrm{sO}_{2}(\%)$ & $48.7 \pm 8.9$ & $49.2 \pm 10.7$ & $49.6 \pm 8.1$ & $48.2 \pm 9.2$ & $88.9 \pm 6.3+\neq \S$ & $99.8 \pm 0.4 \ddagger$ \\
\hline $\mathrm{Hb}(\mathrm{g} / \mathrm{L})$ & $114 \pm 16$ & $112 \pm 13$ & $110 \pm 11$ & $107 \pm 12$ & $101 \pm 12 \uparrow \ddagger$ & $102 \pm 8$ \\
\hline \multicolumn{7}{|c|}{ Control fetal lambs $(n=6)$} \\
\hline $\mathrm{pH}$ & $7.35 \pm 0.04$ & $7.35 \pm 0.03$ & $7.34 \pm 0.03$ & $7.32 \pm 0.02$ & $7.34 \pm 0.04$ & $7.31 \pm 0.05$ \\
\hline $\mathrm{PCO}_{2}(\mathrm{kPa})$ & $7.4 \pm 0.8$ & $7.3 \pm 0.6$ & $7.4 \pm 0.5$ & $7.2 \pm 0.5$ & $6.1 \pm 1.2$ & $6.9 \pm 0.9$ \\
\hline $\mathrm{PO}_{2}(\mathrm{kPa})$ & $2.6 \pm 0.5$ & $3.0 \pm 0.7$ & $3.0 \pm 0.7$ & $3.0 \pm 0.7$ & $5.6 \pm 1.8 \dagger \ddagger$ & $28.6 \pm 16.6$ \\
\hline $\mathrm{SO}_{2}(\%)$ & $44.2 \pm 15.6$ & $47.3 \pm 16.2$ & $46.9 \pm 16.3$ & $47.5 \pm 14.7$ & $78.6 \pm 14.8+\ddagger$ & $97.3 \pm 2.8$ \\
\hline $\mathrm{Hb}(\mathrm{g} / \mathrm{L})$ & $116 \pm 8$ & $118 \pm 8$ & $119 \pm 7$ & $115 \pm 4$ & $112 \pm 8 \dagger$ & $105 \pm 10 \ddagger$ \\
\hline
\end{tabular}

* All data presented as mean \pm SD. Data obtained at baseline before infusion were compared only to data obtained at baseline after infusion. Data obtained during ventilation with $100 \% \mathrm{O}_{2}$ were compared only to data obtained during room air ventilation. For ventilation with $100 \% \mathrm{O}_{2}: n$ $=5$ (meclofenamate-treated group) and $n=4$ (control group). $\mathrm{sO}_{2}$, oxygen saturation.

$\dagger p<0.05 v s$ baseline.

$\ddagger p<0.05$ vs previous condition.

$\S p<0.05$ meclofenamate-treated group vs control group.

Committee on Animal Research at the University of California San Francisco.

Surgical Preparation. Surgery of the ewes was performed under epidural anesthesia with $4 \mathrm{ml}$ of $1 \%$ tetracaine hydrochloride (Pontocaine, Winthrop Pharmaceuticals, New York, NY), i.v. anesthesia with 50 to $100 \mathrm{mg}$ ketamine hydrochloride (Ketaset, Fort Dodge Laboratories, Fort Dodge, IA) as needed, and local anesthesia with $2 \%$ lidocaine hydrochloride (Lidocaine, ElkinsSinn, Cherry Hill, NJ). Fetal incisions were preceded by onetime intramuscular injection of anesthesia with $20 \mathrm{mg}$ ketamine hydrochloride and an administration of local anesthesia with $1 \%$ lidocaine hydrochloride. Fetal breathing movements during surgery were prevented with succinylcholine chloride (Anectine, Burroughs-Wellcome, Research Triangle Park, NC).

Catheters for pressure measurements, infusions, and withdrawals were inserted through two separate uterine incisions. Through a small uterine incision exposing a fetal hind leg, catheters were inserted into a pedal artery and vein and advanced to the descending aorta and the inferior vena cava, respectively. Through a larger uterine incision exposing the left hemithorax and the fetal neck, catheters were inserted into the pulmonary trunk, the right pulmonary artery, the left atrium, the carotid artery (advanced to the ascending aorta), and the external jugular vein (advanced to the superior vena cava). In addition, catheters for pressure measurements were inserted into the trachea and the amniotic cavity.

To prevent constriction of the ductus arteriosus during the subsequent experimental protocol, the adventitia and media of the ductus arteriosus were infiltrated with formalin (13).

For continuous measurements of left pulmonary arterial blood flow and for comparison with our principal method of measuring pulmonary blood flow (radionuclide-labeled microspheres), a 6mm ultrasonic flow transducer (Transonic Systems, Ithaca, NY) was placed around the left pulmonary artery in nine fetal lambs (six treated with meclofenamate and three controls).

For ventilation of the fetus during the experimental protocol and to assure continued unobstructed drainage of tracheal fluid into the amniotic cavity before the experimental protocol, the trachea was intubated as follows. The trachea was dissected and ligated proximally. Through an incision, a $4.5-\mathrm{mm}$ endotracheal tube was advanced toward the carina. Via a Y-connector, the endotracheal tube was connected to two long extension tubes filled with $0.9 \% \mathrm{NaCl}$. One tube was sealed, and the other was connected to a tube in the amniotic cavity.

The incisions in the fetal skin and the uterus were closed after amniotic fluid losses were replaced with warm $0.9 \% \mathrm{NaCl}$. The catheters were filled with heparin sodium (Liquaemin Sodium, $1000 \mathrm{IU} / \mathrm{mL}$, Organon, Inc., West Orange, NJ) and sealed. Then the catheters, the extension tubes, and the flow transducer cable were exteriorized to the left flank of the ewe and protected by a vinyl pouch. Finally, the abdominal incision was closed in layers, and the ewe was allowed to recover. Antibiotics (Penicillin G potassium, 2 million IU, E. R. Squibb \& Sons, Inc., Princeton, NJ, and gentamicin sulfate, $100 \mathrm{mg}$, Elkins-Sinn) were administered i.v. to the ewe and into the amniotic cavity during surgery and daily thereafter.

Experimental Protocol. General. To evaluate the role of PGs as regulators of pulmonary vascular resistance during static and rhythmic distension and during oxygenation of fetal lungs, we studied the sequential effects of these three interventions on pulmonary vascular resistance in seven fetal lambs receiving meclofenamate (a PG synthetase inhibitor) and in six controls receiving vehicle solution. We calculated pulmonary vascular resistance from measurements of pressures in the pulmonary artery and the left atrium and measurements of pulmonary blood flow, using the radionuclide-labeled microsphere method. In addition, we calculated right ventricular cardiac output during baseline, static distension, and rhythmic distension. We also measured descending aortic, tracheal, and amniotic pressures, heart rate, indicators of acid-base status, and the level of oxygenation. All these measurements were obtained both before and after (baseline) a 4-h infusion of meclofenamate or vehicle solution. Measurements were repeated during static distension of the fetal lungs with a gas mixture that did not change fetal $\mathrm{PO}_{2}$ or acid-base status (static distension), during rhythmic distension of the fetal lungs with the same gas mixture as during static distension (rhythmic distension), and finally during rhythmic ventilation of the fetal lungs, first with room air (ventilation with oxygenation) and then with $100 \%$ oxygen. Spontaneous fetal breathing during the study was prevented with succinylcholine chloride.

Baseline. Measurements obtained after $4 \mathrm{~h}$ of infusion were not different from measurements obtained before infusion, with one minor exception: There was a small increase in the pressure gradient across the lungs in the meclofenamate-treated group (Table 2). Therefore, the condition closest in time to the ventilatory interventions (i.e. after $4 \mathrm{~h}$ of meclofenamate or vehicle infusion) is defined as baseline in this study.

Static distension. To achieve homogeneous distension and ventilation of the fetal lungs, artificial surfactant (Exosurf, gen- 
Table 2. Pulmonary hemodynamic and blood flow data for fetal lambs treated with meclofenamate*

\begin{tabular}{|c|c|c|c|c|c|c|}
\hline & $\begin{array}{c}\text { Baseline } \\
\text { before } 4 \mathrm{~h} \\
\text { infusion }\end{array}$ & $\begin{array}{l}\text { Baseline } \\
\text { after } 4 \mathrm{~h} \\
\text { infusion }\end{array}$ & $\begin{array}{c}\text { Distension with } \\
\text { nitrogen (static } \\
\text { distension) }\end{array}$ & $\begin{array}{l}\text { Ventilation with } \\
\text { nitrogen (rhythmic } \\
\text { distension) }\end{array}$ & $\begin{array}{l}\text { Ventilation } \\
\text { with room air } \\
\text { (ventilation + } \\
\text { oxygenation) }\end{array}$ & $\begin{array}{c}\text { Ventilation } \\
\text { with } 100 \% \\
\mathrm{O}_{2} \\
\end{array}$ \\
\hline \multicolumn{7}{|c|}{ Meclofenamate-treated fetal lambs $(n=7)$} \\
\hline PVR $\left(\mathrm{kPa} / \mathrm{mL} / \mathrm{min} \cdot \mathrm{kg}^{-1}\right)$ & $0.32 \pm 0.16$ & $0.33 \pm 0.25$ & $0.46 \pm 0.26$ & $0.20 \pm 0.14 \dagger \ddagger$ & $0.02 \pm 0.01 \uparrow \S$ & $0.02 \pm 0.01$ \\
\hline $\mathrm{PBF}(\mathrm{mL} / \mathrm{min} / \mathrm{kg})$ & $27 \pm 16$ & $37 \pm 33$ & $22 \pm 19$ & $53 \pm 36 \dagger$ & $277 \pm 113+\S$ & $269 \pm 91$ \\
\hline PA-LA (kPa) & $6.7 \pm 0.7$ & $7.2 \pm 0.7 \dagger$ & $6.8 \pm 0.5$ & $7.1 \pm 0.9$ & $6.0 \pm 0.9+\S$ & $6.0 \pm 0.8$ \\
\hline $\mathrm{PA}(\mathrm{kPa})$ & $7.2 \pm 0.8$ & $7.6 \pm 0.7$ & $7.3 \pm 0.5$ & $7.9 \pm 1.2$ & $7.3 \pm 1.1$ & $6.9 \pm 0.8$ \\
\hline $\mathrm{LA}(\mathrm{kPa})$ & $0.5 \pm 0.3$ & $0.4 \pm 0.3$ & $0.5 \pm 0.1$ & $0.8 \pm 0.3$ & $1.3 \pm 0.3 \uparrow \S$ & $0.9 \pm 0.1$ \\
\hline \multicolumn{7}{|l|}{ Control fetal lambs $(n=6)$} \\
\hline $\operatorname{PVR}\left(\mathrm{kPa} / \mathrm{mL} / \mathrm{min} \cdot \mathrm{kg}^{-1}\right)$ & $0.43 \pm 0.24$ & $0.27 \pm 0.15$ & $0.43 \pm 0.33$ & $0.07 \pm 0.04 \uparrow \S$ & $0.02 \pm 0.01 \uparrow \S$ & $0.02 \pm 0.01$ \\
\hline $\mathrm{PBF}(\mathrm{mL} / \mathrm{min} / \mathrm{kg})$ & $26 \pm 24$ & $34 \pm 17$ & $44 \pm 62$ & $117 \pm 70 \dagger \S$ & $266 \pm 97+\S$ & $299 \pm 165$ \\
\hline$\triangle \mathrm{PA}-\mathrm{LA}(\mathrm{kPa})$ & $7.1 \pm 0.7$ & $7.1 \pm 0.8$ & $7.2 \pm 1.3$ & $6.4 \pm 1.3 \dagger$ & $5.5 \pm 0.8 \S$ & $5.7 \pm 0.7$ \\
\hline $\mathrm{PA}(\mathrm{kPa})$ & $7.2 \pm 0.7$ & $7.2 \pm 0.5$ & $7.5 \pm 1.2$ & $7.2 \pm 1.1$ & $6.4 \pm 0.7 \S$ & $6.3 \pm 0.7$ \\
\hline $\mathrm{LA}(\mathrm{kPa})$ & $0.1 \pm 0.3$ & $0.1 \pm 0.4$ & $0.3 \pm 0.4$ & $0.8 \pm 0.4$ & $0.9 \pm 0.3$ & $0.5 \pm 0.3$ \\
\hline
\end{tabular}

* All data presented as mean \pm SD. Data obtained at baseline before infusion were compared only with data obtained at baseline after infusion. Data obtained during ventilation with $100 \% \mathrm{O}_{2}$ were compared only to data obtained during room air ventilation. For ventilation with $100 \% \mathrm{O}_{2}: n$ $=5$ (meclofenamate-treated group) and $n=4$ (control group). PVR, pulmonary vascular resistance; PBF, pulmonary blood flow; $\triangle \mathrm{PA}-\mathrm{LA}$, difference between mean pulmonary artery pressure and mean left atrium pressure; PA, mean pulmonary artery pressure; LA, mean left atrium pressure.

$\dagger p<0.05 v s$ previous condition

$\ddagger p<0.05$ meclofenamate-treated group vs control group.

$\S p<0.05$ vs baseline.

erously supplied by Dr. Walker Long; Burroughs-Wellcome) was instilled via an extension tube into the trachea $1 \mathrm{~h}$ before static distension. Immediately before distension, the two extension tubes connected to the endotracheal tube were opened, and lung liquid was allowed to drain. Then a gas mixture of approximately $3 \% \mathrm{O}_{2}, 5 \% \mathrm{CO}_{2}$, and $92 \% \mathrm{~N}_{2}$, adjusted for each fetus to match $\mathrm{PO}_{2}$ and $\mathrm{PCO}_{2}$ in the descending aorta, was allowed to flush the tubing system. Next, the lungs were distended for $30 \mathrm{~min}$ to tracheal pressures of $3.1 \pm 0.5 \mathrm{kPa}$ (meclofenamate-treated lambs) and $2.7 \pm 0.1 \mathrm{kPa}$ (control lambs) (Table 3). Measurements were obtained between 15 and $30 \mathrm{~min}$, at which time the changes induced by the intervention had stabilized.

Rhythmic distension. The fetal lungs then were distended rhythmically for 30 min with a model 665 respirator (Harvard Apparatus, Millis, MA) at a rate of 40 respirations per min and with an inspiratory:expiratory ratio of 0.45 . The peak inspiratory and peak end expiratory pressures are summarized in Table 3. The same gas mixture was used as for static distension. Measurements were obtained between 15 and $30 \mathrm{~min}$, at which time the changes induced by the intervention had stabilized.

Ventilation with oxygenation. The gas mixture was then changed to room air for $30 \mathrm{~min}$ and finally to $100 \% \mathrm{O}_{2}$ for 30 min. A small amount of $\mathrm{CO}_{2}$ was added to both gas mixtures to keep $\mathrm{pH}$ and $\mathrm{PCO}_{2}$ constant. Then, using the same ventilatory settings (Table 3 ) and protocol as described for rhythmic distension, measurements were obtained first during room-air ventilation and then during $100 \% \mathrm{O}_{2}$ ventilation. Measurements obtained during room-air ventilation $(n=13)$ were not different

Table 3. Ventilatory settings in fetal lambs treated with meclofenamate*

\begin{tabular}{|c|c|c|c|}
\hline & $\begin{array}{c}\text { Static dis- } \\
\text { tension }\end{array}$ & $\begin{array}{l}\text { Rhythmic } \\
\text { distension }\end{array}$ & $\begin{array}{c}\text { Ventilation + } \\
\text { oxygenation }\end{array}$ \\
\hline \multicolumn{4}{|c|}{ Meclofenamate-treated fetal lambs $(n=7)$} \\
\hline Mean airway pressure & $3.1 \pm 0.5$ & & \\
\hline Peak inspiratory pressure & & $3.3 \pm 0.4 \dagger$ & $2.9 \pm 0.4$ \\
\hline Peak end expiratory pressure & & $0.8 \pm 0.4 \dagger$ & $0.4 \pm 0.7$ \\
\hline \multicolumn{4}{|l|}{ Control fetal lambs $(n=6)$} \\
\hline Mean airway pressure & $2.7 \pm 0.1$ & & \\
\hline Peak inspiratory pressure & & $2.5 \pm 0.4$ & $2.7 \pm 0.5$ \\
\hline Peak end expiratory pressure & & $0.0 \pm 0.8$ & $0.0 \pm 0.8$ \\
\hline
\end{tabular}

$*$ All data presented as mean $\pm \mathrm{SD}$. Pressures are in $\mathrm{kPa}$.

$\dagger p<0.05 v s$ control fetal lambs. from measurements obtained during $100 \% \mathrm{O}_{2}$ ventilation $(n=$ 9 ) in either group, with the exception of the level of oxygenation (Table 1). Therefore, measurements obtained during room-air ventilation were used for analysis.

Meclofenamate infusion. Exactly $35 \mathrm{mg}$ of the cyclooxygenase inhibitor meclofenamate sodium monohydrate (generously supplied by Parke Davis, Ann Arbor, MI) were dissolved in a solution of $5.8 \mathrm{~mL} 0.9 \% \mathrm{NaCl}, 0.2 \mathrm{~mL} \mathrm{Na} \mathrm{CO}_{3}(7.15 \mathrm{~g} / \mathrm{L})$, and $4 \mathrm{~mL}$ distilled water (bolus infusion) and in a solution of $29 \mathrm{~mL}$ $0.9 \% \mathrm{NaCl}, 1 \mathrm{~mL} \mathrm{Na}_{2} \mathrm{CO}_{3}$, and $20 \mathrm{~mL}$ distilled water (continuous infusion). An i.v. bolus injection of $9.0 \pm 1.3 \mathrm{mg} / \mathrm{kg}$ (mean \pm $\mathrm{SD}$ ) given over 5 to $10 \mathrm{~min}$ was followed by a continuous infusion of $1.4 \pm 0.3 \mathrm{mg} / \mathrm{kg} / \mathrm{h}$ for $5 \mathrm{~h}$. This particular infusion protocol has been shown previously to block PG synthesis (14).

Completion of protocol. At the end of the study, the ewe was killed with large doses of pentobarbital sodium (Euthanasia C II, Anthony Products Co., Arcadia, CA). The fetus was removed from the uterus and weighed. Catheter positions and the appearance of the lungs were evaluated.

Methods of Measurement and Calculation. Pulmonary vascular resistance. Pulmonary vascular resistance was calculated as the difference between mean pulmonary arterial and mean left atrial pressures divided by pulmonary blood flow per $\mathrm{kg}$ fetal weight.

Pressures. Mean and phasic pressures in the descending aorta, pulmonary artery, left atrium, and trachea and mean pressures in the amniotic cavity (zero reference) were measured continuously using repeatedly calibrated $\mathrm{P} 23 \mathrm{Db}$ pressure transducers (Statham Instruments, Oxnard, CA) and an R611 direct-writing polygraph (Beckman Instruments, Schiller Park, IL). For technical reasons, pressures in the left atrium could not be measured in two fetal lambs (one in each group), and mean values from the other fetal lambs were assigned. Heart rate was measured continuously from the arterial pressure, using a cardiotachometer.

Pulmonary blood flow. Pulmonary blood flow was calculated by the radionuclide-labeled microsphere method (15). Microspheres of $15 \mu \mathrm{m}$, selected from ${ }^{57} \mathrm{Co},{ }^{51} \mathrm{Cr},{ }^{153} \mathrm{Gd},{ }^{114} \mathrm{In},{ }^{54} \mathrm{Mn}$, ${ }^{95} \mathrm{Nb},{ }^{113} \mathrm{Sn},{ }^{85} \mathrm{Sr}$, and ${ }^{65} \mathrm{Zn}$ (New England Nuclear, Boston, MA) were injected into the superior vena cava. A reference sample was obtained from the right pulmonary artery at approximately $4 \mathrm{~mL} / \mathrm{min}$, beginning immediately before the injection of microspheres and continuing for 30 to $40 \mathrm{~s}$ after completion of the injection. The volume of blood removed for sampling was re- 
placed by an equal volume of fetal blood or, if unavailable, of maternal blood. At the completion of the protocol, both lungs were dissected, weighed, fixed in formalin, cut into small pieces, and placed in counting vials. The radioactivities of lung tissue and of reference blood samples were counted in a 1000-channel multichannel pulse-height analyzer (Norland, Fort Atkinson, WI). Sp act of each isotope within a sample was calculated by the least-squares method (15). The method of calculating pulmonary blood flow, using injection of microspheres into the superior vena cava and withdrawal from the (right) pulmonary artery, is conventional when right ventricular cardiac output is the only contributor to pulmonary blood flow (as is the case in the unventilated fetus, with the exception of the small contribution of the bronchial circulation). Right ventricular cardiac output remains the only important contributor to pulmonary blood flow during static and rhythmic distension (16). However, during in utero ventilation with oxygenation, a substantial ductus arteriosus left to right shunt develops (16), so pulmonary blood flow is then determined by contributions from both the right and left ventricular cardiac outputs. Therefore, validation of our method of calculating pulmonary blood flow (injection into the superior vena cava and withdrawal from the right pulmonary artery) during this condition was needed.

Validation of pulmonary blood flow measurements. To validate our method of calculating pulmonary blood flow during ventilation with oxygenation, we also injected microspheres into the left atrium. If the reference sample from the right pulmonary artery contains a completely mixed sample of contributions from the right and left ventricles, calculated pulmonary blood flow from microsphere injections into the superior vena cava and the left atrium should be the same.

In addition, in nine fetal lambs (six treated with meclofenamate and three controls) left pulmonary arterial blood flow was measured continuously using a T101 ultrasonic blood flowmeter (Transonic Systems) and compared with the left pulmonary blood flow measured by the microsphere method as above.

Right ventricular cardiac output. Right ventricular cardiac output was calculated during baseline and during static and rhythmic distension as follows. The counts in the superior vena caval injection were divided by the counts in the right pulmonary arterial reference sample and then multiplied by the flow rate of the right pulmonary arterial reference sample. This approach is possible because superior vena caval blood returns almost exclusively to the right ventricle in the fetal circulation (1). Pulmonary blood flow as a percentage of right ventricular cardiac output was then calculated.

Acid-base status and oxygenation. Fetal blood samples were obtained from the descending aorta for measurements of $\mathrm{pH}$, $\mathrm{PO}_{2}, \mathrm{PCO}_{2}$, using a model 158 Blood Gas Analyzer (Corning Medical, Medfield, MA), Hb concentration, and oxygen saturation, using a model OSM2 Hemoximeter (Radiometer, Copenhagen, Denmark).

Statistical Analysis. All data are presented as mean \pm 1 SD. Comparisons within the meclofenamate-treated group and within the control group were made by analysis of variance for repeated measures. Differences were then identified using paired $t$ tests (17). Data obtained during each experimental condition were compared with baseline ( $a$ priori) and with the immediately preceding condition. Comparisons between measurements in the meclofenamate-treated group and the control group were made using nonpaired $t$ tests. Appropriate Bonferroni corrections were applied for comparisons other than a priori. Statistical significance was considered present for a $p$ value $<0.05$.

\section{RESULTS}

Inhibition of PG synthesis with meclofenamate had an influence on pulmonary vascular resistance during rhythmic distension but not during static distension or ventilation with oxygen- ation (Table 2). During rhythmic distension, there was no change in pulmonary vascular resistance from baseline in the meclofenamate-treated fetal lambs (Fig. 1). In contrast, pulmonary vascular resistance decreased 4-fold in the control group. The difference in pulmonary vascular resistance between meclofenamate-treated fetal lambs and controls during rhythmic distension was 3-fold (Table 2). During static distension, pulmonary vascular resistance did not change from baseline in either group. During ventilation with oxygenation, pulmonary vascular resistance decreased 12-fold from baseline in both groups.

Large increases in pulmonary blood flow and small decreases in the pressure difference across the lungs were responsible for the changes in pulmonary vascular resistance (Table 2). During baseline, both determinants of pulmonary vascular resistance were normal (16) and were not different between the two groups. During rhythmic distension, neither pulmonary blood flow nor the pressure difference across the lungs changed from baseline in the meclofenamate-treated fetal lambs. In contrast, in the control group, pulmonary blood flow increased more than 3-fold, and the pressure difference across the lungs decreased by $10 \%$. During static distension, pulmonary blood flow and the pressure difference across the lungs did not change from baseline in either group. During ventilation with oxygenation, pulmonary blood flow increased more than 7 -fold from baseline in both groups. In addition, there was a $16 \%$ decrease in the pressure difference across the lungs in the meclofenamate-treated group. This decrease in the pressure difference was due to a statistically insig. nificant decrease in the mean pulmonary arterial pressure and to a doubling of the mean left atrial pressure.

The individual responses of pulmonary blood flow during rhythmic and static distension varied. During rhythmic distension in the meclofenamate-treated group, pulmonary blood flow increased more than 2 -fold in three of the seven fetal lambs, increased minimally in two of the seven, and decreased in the remaining two lambs. In contrast, during rhythmic distension in the control group, pulmonary blood flow increased more than 3 -fold in five of the six fetal lambs and increased minimally in one fetal lamb. During static distension, pulmonary blood flow decreased in five of the seven fetal lambs in the meclofenamatetreated group (different subset than during rhythmic distension) and in four of the six controls. A comparison of these nine fetal lambs with a decrease in pulmonary blood flow (and an increase in pulmonary vascular resistance) with the four fetal lambs with an increase in pulmonary blood flow showed that the decrease in pulmonary blood flow was due to a decrease in right ventricular cardiac output and to a decreased percentage of right ventricular cardiac output distributed to the lungs (Table 4).

Additional information on left pulmonary arterial blood flow by continuous measurement with the ultrasonic flowmeter showed that pulmonary blood flow increased gradually over 10 to 15 min during ventilation with oxygenation in the meclofen-

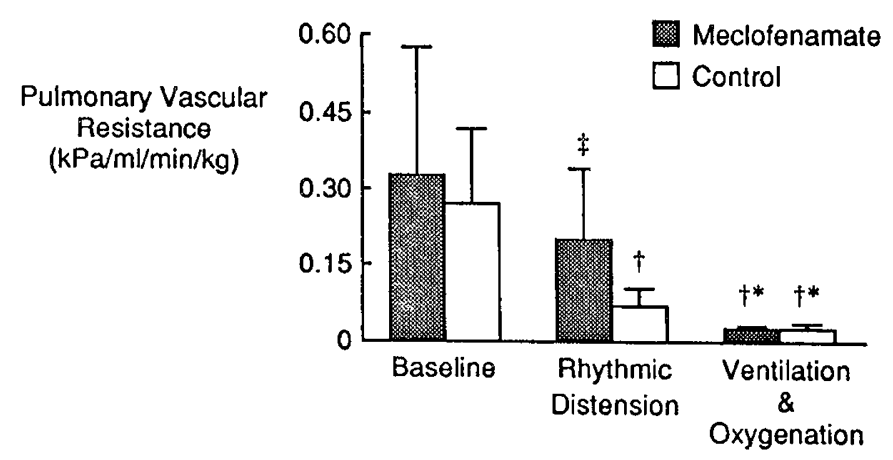

Fig. 1. Pulmonary vascular resistance during rhythmic distension and ventilation with oxygenation in seven meclofenamate-treated fetal lambs and six control fetal lambs. All data are presented as mean $\pm \mathrm{SD} . \dagger, p<$ 0.05 vs baseline; ${ }^{*}, p<0.05$ ventilation and oxygenation $v s$ rhythmic distension; $¥ p<0.05$ meclofenamate $v s$ control. 
Table 4. Right ventricular cardiac output during static distension in fetal lambs*

\begin{tabular}{lcc}
\hline & $\begin{array}{c}\text { Fetal lambs with } \\
\text { decrease in PBF } \\
(n=9)\end{array}$ & $\begin{array}{c}\text { Fetal lambs with } \\
\text { increase in PBF } \\
(n=4)\end{array}$ \\
\hline RV CO (mL/min/kg) & $176 \pm 35 \dagger$ & $218 \pm 20$ \\
Change in RV CO from & $-75 \pm 42 \ddagger$ & $19 \pm 40$ \\
BL (mL/min/kg) & $-12 \pm 15 \S$ & $25 \pm 31$ \\
$\begin{array}{c}\text { Change in \% of RV CO } \\
\text { to lungs from BL (\%) }\end{array}$ & & \\
\hline
\end{tabular}

* All data presented as mean $\pm \mathrm{SD}$. PBF, pulmonary blood flow; RV $\mathrm{CO}$, right ventricular cardiac output; $\mathrm{BL}$, baseline.

$\dagger p=0.06 v s$ fetal lambs with an increase in PBF.

$\ddagger p<0.01$.

$\S p<0.025$.

amate-treated fetal lambs (Fig. 2) and during rhythmic distension in the control group. After discontinuation of ventilation, pulmonary blood flow gradually (again over $10-15 \mathrm{~min}$ ) returned to baseline values. During static distension, heart rate and pressures in the descending aorta fell abruptly and slowly returned toward baseline (Fig. 3). During static distension, pulmonary blood flow decreased slightly and gradually in nine of 13 fetal lambs.

Measurements of left pulmonary blood flow with microspheres correlated very well with measurements with the ultrasonic flowmeter $\left[y=1.248 x+20.1, r=0.958, r^{2}=0.918, n=57(y=\right.$ pulmonary blood flow by microspheres, $x=$ pulmonary blood flow by ultrasonic flowmeter)]. These measurements were obtained over a large range of values $(3-612 \mathrm{~mL} / \mathrm{min})$. During ventilation with oxygenation, there was no difference and there was a good correlation between pulmonary blood flow measured by injecting microspheres into the superior vena cava and pulmonary blood flow measured by injecting microspheres into the left atrium $[1064 \pm 345$ versus $967 \pm 261 \mathrm{~mL} / \mathrm{min} / \mathrm{kg}$ (mean \pm $\left.\mathrm{SD}), r=0.827, r^{2}=0.684, n=10\right]$.

There were no changes in $\mathrm{pH}, \mathrm{PCO}_{2}$, or $\mathrm{Hb}$ concentration during the experimental protocol (Table 1). The $\mathrm{PO}_{2}$ and oxygen saturation increased substantially during ventilation with room air and further during ventilation with $100 \% \mathrm{O}_{2}$. Despite these further increases in $\mathrm{PO}_{2}$ and oxygen saturation during $100 \% \mathrm{O}_{2}$ ventilation, all the oxygenation-related changes in pulmonary vascular resistance occurred during room-air ventilation. There were no changes in the heart rate or in the mean pressure in the descending aorta during the experimental protocol.

\section{DISCUSSION}

This study in fetal lambs shows that PGs are indeed important regulators of pulmonary vascular resistance during rhythmic distension of the lungs. Evidence for their importance is that during rhythmic distension, pulmonary vascular resistance did not change significantly from baseline in the fetal lambs treated with the PG synthetase inhibitor, meclofenamate, but decreased 4 -fold in the control group. The large decrease in pulmonary vascular resistance in the control group was mainly the result of an increase in pulmonary blood flow. The magnitude of this increase was similar to that observed in previous reports in which PG metabolism was not modified $(16,18)$. This role of PGs during rhythmic distension is in accord with previous findings in acutely exteriorized fetal lambs in which $\mathrm{PGI}_{2}$ was produced by the lungs during rhythmic distension (11). Other PGs besides $\mathrm{PGI}_{2}$ that could be involved in the regulation of pulmonary vascular resistance during rhythmic distension are the vasodilating $\mathrm{PGs}, \mathrm{PGE}_{2}$, and $\mathrm{PGD}_{2}$ (3). The vasodilating properties of $\mathrm{PGD}_{2}$ are unique for the immediate perinatal period (19). However, the predominant $\mathrm{PG}$ involved is probably $\mathrm{PGI}_{2}(3)$, which is produced by endothelial cells in response to shear stresses and other stimuli (20).

This study also shows that PG are not essential for the regulation of pulmonary vascular resistance during ventilation with oxygenation. Evidence for this conclusion is that with oxygenation, pulmonary vascular resistance decreased 12 -fold from baseline in both the meclofenamate-treated and the control fetal lambs. Interestingly, the level of oxygenation did not affect the magnitude of decrease in pulmonary vascular resistance. The decrease in pulmonary vascular resistance was maximal during ventilation with room air. This decrease in pulmonary vascular resistance is very similar to that normally seen at birth (2). An implication of this finding for studies where experimental animals are simultaneously exposed to rhythmic distension and oxygenation is that the importance of PGs during rhythmic distension may be masked or altered by changes induced by other mechanisms during oxygenation. These other mechanisms most likely involve the vasodilator peptide, bradykinin, which is produced by the lungs during oxygenation (21). Bradykinin may exert its effect either directly or by stimulating endotheliumderived relaxing factor, a potent vasodilator $(20)$ produced by the endothelium of pulmonary arteries of newborn guinea pigs (22). Although bradykinin effects also may be mediated by PGs (23), this specific mechanism is unlikely to be of major importance during the transitional period, based on the findings of this study.

Finally, this study shows that PGs do not alter the regulation of pulmonary vascular resistance during static distension. Pulmonary vascular resistance did not change from baseline in either group during static distension (Table 2). The lack of change in pulmonary vascular resistance during static distension is difficult to interpret without additional measurements of lung volumes, alveolar surface tension, pleural pressures, and lung liquid status. Static distension results in a complex series of mechanical and
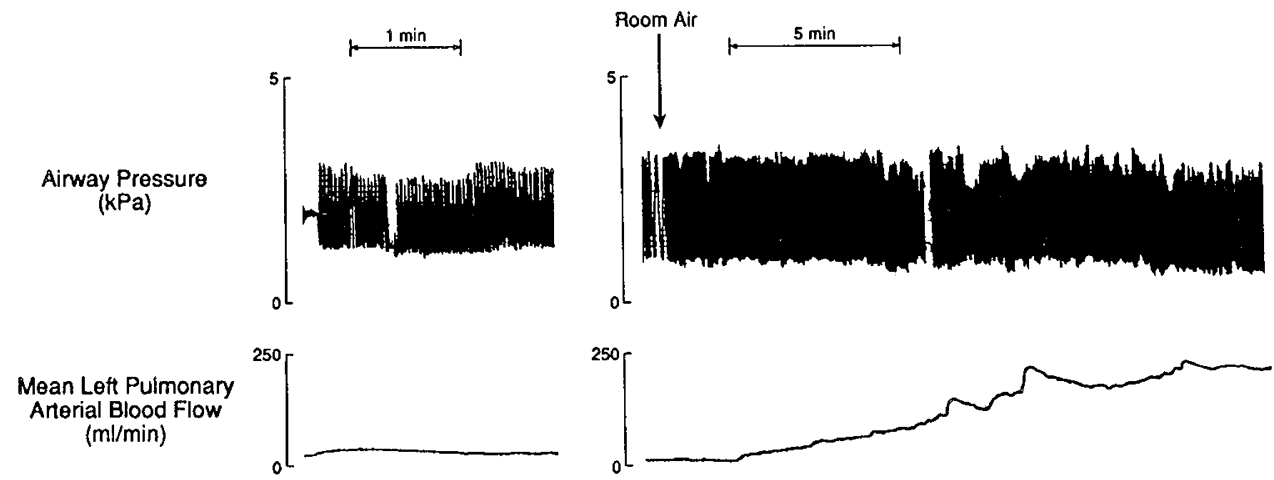

Fig. 2. Phasic airway pressures and mean left pulmonary artery blood flow in one meclofenamate-treated fetal lamb. Pulmonary arterial blood flow was measured continuously with an ultrasonic flow transducer. The arrow indicates the change from a gas mixture of $3 \% \mathrm{O}_{2}$ to room air whereas the phasic airway pressures remained constant. Note that pulmonary blood flow did not change during rhythmic distension (left panel). In contrast, pulmonary blood flow increased gradually during ventilation with oxygenation (right panel). 

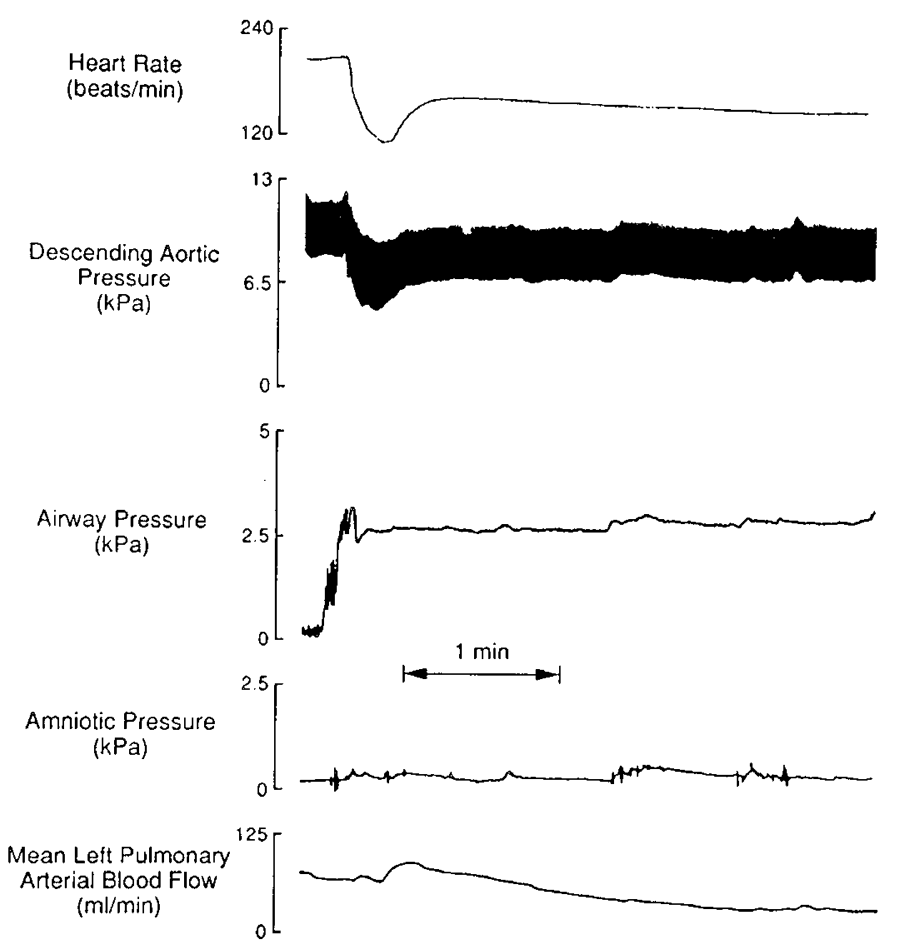

Fig. 3. Heart rate, descending aortic, airway, and amniotic pressures, and mean left pulmonary arterial blood flow during static distension in one control fetal lamb. The illustrated responses were typical for both the meclofenamate-treated fetal lambs and the controls. Note that the distending pressure in the airway was kept constant.

neurohumoral changes, which may affect pulmonary vascular resistance in opposite directions. Mechanical changes that lead to decreased pulmonary vascular resistance include decreased alveolar surface tension and interstitial fluid pressure during gaseous distension (24) and movement of airway fluid into the capillaries (25). Previous studies showing a decrease in pulmonary vascular resistance differed from our study in two important aspects. First, we applied distension continuously for $30 \mathrm{~min}$ (Fig. 3), whereas in one of the previous studies (26), distension was brief and was followed by a large increase in pulmonary blood flow. Second, the airway pressure during distension in our study was higher than in a previous study (27). Mechanical factors that may increase pulmonary vascular resistance include expansion at high lung volumes (28) and an expansion-related decrease in right ventricular cardiac output. In the majority of fetal lambs in this study, right ventricular cardiac output decreased during static distension (Table 4). The most important reasons for this are probably a decrease in venous return and an increase in right ventricular afterload.

Two aspects of the study design merit comment. First, in this study, changes in pulmonary vascular resistance resulting from constriction of the ductus arteriosus were prevented by infiltration of formalin into the adventitia and media of the ductus arteriosus. Consequently, changes in pulmonary vascular resistance were primarily due to changes in pulmonary blood flow and not to substantial changes in pulmonary arterial pressures. In two fetal lambs excluded from analysis because of inadequate formalin treatment, meclofenamate alone caused pulmonary hypertension and increased pulmonary blood flow 3- to 5-fold in the $1 \mathrm{st} h$ of infusion. The increase in pulmonary blood flow from meclofenamate confirms findings by others (29). Ductal constriction is the likely mechanism. We believe, therefore, that studies on the regulation of pulmonary vascular resistance involving PG synthetase inhibition must be performed with a fixed diameter of the ductus arteriosus. Second, the differences in ventilatory settings during rhythmic distension between the meclofenamate-treated group and the controls (Table 3) are unlikely causes for the observed difference in pulmonary vascular resistance. One reason is that the hemodynamic status and, specifically, the right ventricular cardiac output were similar for the two groups. Another reason is that adequacy of ventilation, as judged by the arterial $\mathrm{PO}_{2}$ achieved during ventilation with oxygenation, was similar in the two groups.

In conclusion, this study shows that PG are important regulators of pulmonary vascular resistance during rhythmic distension of the lungs in fetal lambs. In addition, PGs are not essential in the regulation of pulmonary vascular resistance during ventilation with oxygenation. Finally, static distension with or without PG inhibition does not decrease pulmonary vascular resistance.

Acknowledgments. The authors acknowledge the expert technical assistance of Christine Roman, Roger Chang, Mario Trujillo, Carl McWatters, and Bruce Payne and thank Mimi Zeiger for her critical review of the manuscript.

\section{REFERENCES}

1. Heymann MA 1989 Fetal and neonatal circulations. In: Adams FH, Emmanouilides GC, Riemenschneider TA (eds) Heart Disease in Infants, Children, and Adolescents, 4th Ed. Williams \& Wilkins, Baltimore, pp 24-35

2. Heymann MA 1984 Control of the pulmonary circulation in the perinatal period. J Dev Physiol 6:281-290

3. Cassin S 1987 Role of prostaglandins, thromboxane and leukotrienes in the control of the pulmonary circulation in the fetus and newborn. Semin Perinatol 11:53-63

4. Leffler CW, Hessler JR, Terragno NA 1980 Ventilation-induced release of prostaglandin-like material from fetal lungs. Am J Physiol 238:H282-H286

5. Leffler CW, Hessler JR, Green RS 1984 The onset of breathing at birth stimulates pulmonary vascular prostacyclin synthesis. Pediatr Res 18:938942

6. Leffler CW, Tyler TL, Cassin S 1978 Effect of indomethacin on pulmonary vascular response to ventilation of fetal goats. Am J Physiol 234:H346-H351

7. Davidson D 1988 Pulmonary hemodynamics at birth: effect of acute cyclooxygenase inhibition in lambs. J Appl Physiol 64:1676-1682

8. Teitel DF, Iwamoto HS, Rudolph AM 1990 Changes in the pulmonary circulation during birth-related events. Pediatr Res 27:372-378

9. Cassin S, Dawes GS, Mott JC, Ross BB, Strang LB 1964 The vascular resistance of the foetal and newly ventilated lung of the lamb. J Physiol (Lond) 171:6179

10. Morin III FC, Egan EA, Norfleet WT 1988 Indomethacin does not diminish the pulmonary vascular response of the fetus to increased oxygen tension. Pediatr Res 24:696-700

11. Leffler CW, Hessler JR, Green RS 1984 Mechanism of stimulation of pulmonary prostacyclin synthesis at birth. Prostaglandins 28:877-887

12. Iwamoto HS, Teitel D, Rudolph AM 1987 Effect of birth-related events on blood flow distribution. Pediatr Res 22:634-640

13. Rudolph AM, Heymann MA, Fishman N, Lakier JB 1975 Formalin infiltration of the ductus arteriosus: a method for palliation of infants with selected congenital cardiac lesions. N Engl J Med 292:1263-1268

14. Wallen LD, Murai DT, Clyman RI, Lee CH, Mauray FE, Kitterman JA 1988 Effects of meclofenamate on breathing movements in fetal sheep before delivery. J Appl Physiol 64:759-766

15. Hoffman JIE, Payne B, Heymann MA, Rudolph AM 1983 The use of microspheres to measure blood flow. In: Linden RJ (ed) Cardiovascular Physiology, Techniques in the Life Sciences, Vol P 3/1:P304. Elsevier Scientific Publishers Ireland Ltd., County Clare, Ireland, pp P304/1-36

16. Teitel DF, Iwamoto HS, Rudolph AM 1987 Effects of birth-related events on central blood flow patterns. Pediatr Res 22:557-566

17. Glantz SA 1987 Primer of Biostatistics. McGraw-Hill, New York, pp 276-277

18. Blanco CE, Martin CB, Rankin J, Landauer M, Phernetton T 1988 Changes in fetal organ flow during intrauterine mechanical ventilation with or without oxygen. J Dev Physiol 10:53-62

19. Cassin S, Tod M, Philips J, Frisinger J, Jordan J, Gibbs C 1981 Effects of prostaglandin $\mathrm{D}_{2}$ on perinatal circulation. Am J Physiol 240:H755-H760

20. Vane JR, Anggård EE, Botting RM 1990 Regulatory functions of the vascular endothelium. N Engl J Med 323:27-36

21. Heymann MA, Rudolph AM, Nies AS, Melmon KL 1969 Bradykinin production associated with oxygenation of the fetal lamb. Circ Res 25:521-534

22. Davidson D, Eldemerdash A 1990 Endothelium-derived relaxing factor: presence in pulmonary and systemic arteries of the newborn guinea pig. Pediatr Res 27:128-132

23. Frantz E, Soifer SJ, Clyman RI, Heymann MA 1989 Bradykinin produces 
pulmonary vasodilatation in fetal lambs: the role of prostaglandin production. J Appl Physiol 67:1512-1517

24. Nieman GF, Hakim TS, Bredenburg CE 1988 Effect of increased alveolar surface tension on segmental pulmonary vascular resistance. J Appl Physiol 64:154-161

25. Bland RD, Hansen TN, Habakern CM, Bressack MA, Hazinski TA, Raj JU, Goldberg RB 1982 Lung fluid balance in lambs before and after birth. J Appl Physiol 53:992-1004

26. Colebatch HJH, Dawes GS, Goodwin JW, Nadeau RA 1964 The nervous control of the circulation in the foetal and newly expanded lungs of the lamb. J Physiol (Lond) 178:544-562
27. Ikegami M, Jobe A, Berry D, Elkady T, Pettezanno A, Seidner S 1987 Effects of distension of the preterm fetal lamb lung on lung function with ventilation. Am Rev Respir Dis 135:600-606

28. Hakim TS, Michel RP, Chang HK 1982 Effect of lung inflation on pulmonary vascular resistance by arterial and venous occlusion. J Appl Physiol 53:11101115

29. Savich RD, Guerra FA, Lee CH, Kitterman JA 1987 Effects of meclofenamate on fetal breathing movements and pulmonary blood flow. Pediatr Res $21: 221 \mathrm{~A}($ abstr)

\section{Announcement}

\section{Scientific Meeting}

The Society for Behavioral Pediatrics will conduct its 9th Annual Scientific Meeting and Workshops on September 21-23, 1991 at the Omni Inner Harbor Hotel in Baltimore, MD. For further information and registration forms, please contact Ms. Noreen Spota at (215) 248-9168. 